\title{
Os rumos da centralização agrícola e industrial no Brasil: ${ }^{1}$
}

a agricultura nacional segundo André Rebouças

\author{
The direction of agricultural and industrial centralization in \\ Brazil: the national agriculture in the vision of André Rebouças
}

\author{
Roberta Barros Meira ${ }^{2}$
}

\section{RESUMO}

Ao pensarmos na produçáo açucareira do tinal no XIX, deparamo-nos com um setor em crise que precisava de capitais para implementar o moderno maquinismo adotado já há algum tempo pelos países concorrentes. $O$ presente trabalho indaga-se sobre a importância das idéias de André Rebouças em relação às demandas da indústria sacarina no seu trabalho intitulado "Agricultura nacional e estudos econômicos". Assim, o objetivo deste estudo é relacionar os temas abordados por Rebouças, arguto observador de seu tempo, principalmente no que tange a problemática enfrentada pela indústria sacarina e as idéias correntes neste período sobre a viabilidade da adoção da centralização agrícola e industrial no Brasil.

Palavras-Chave: Rebouças. Centralização industrial. Engenhos centrais. Açúcar. Modernização.

\section{ABSTRACT}

When we consider the sugar cane production from the end of the nineteenth century in Brazil, we taced with a crisis in that sector that needed more capital to implement modern machinery, as far adopted by other competitors countries. Here, we discuss the importance of the André Rebouças ideas on sugar industry requirements, issues raised in his paper entitled "Agricultura nacional e estudos econômicos" ("National agriculture and economic studies"). Therefore, the aims of this study is to link the topics covered by Rebouças, an astute observer of his time, especially regarding the problems handled by sugar industry in that period and the ideas about the feasibility of adopting the Brazilian agricultural and industrial centralization.

Keywords: Rebouças. Centralization of agriculture. Central sugar mills. Sugar. Modernization.

\footnotetext{
${ }^{1}$ Este texto vai de encontro ao trabalho desenvolvido na minha pesquisa de Doutorado financiada pela FAPESP.

${ }^{2}$ Doutoranda do Programa de História Econômica, da USP.
} 
Não parece fácil determinar a época em que o atraso da indústria sacarina foi percebido pela elite agrária como um problema que precisava ser debelado e a ânsia de modernizá-la açodou as propostas e medidas tanto dos produtores quanto do Estado. Mas deve ser tida em conta não só uma ênfase maior no discurso dos seus atores, mas também o incremento das políticas agrícolas no final do século XIX.

No Brasil, esta aspiração por mudanças seria um reflexo da adoção de novos maquinismos pelos principais concorrentes do açúcar brasileiro e a perda gradativa do mercado externo. Nos meados do século XIX, os produtores de açúcar enfrentaram uma nova queda na venda dos seus produtos no mercado internacional. Tal fato se deu pela concorrência cada vez maior dos engenhos antilhanos e do aumento sempre crescente da produção do açúcar de beterraba $^{3}$. Esses novos produtores contavam com um maquinário mais moderno que o utilizado no Brasil, além de disporem de mercados certos, como no caso do açúcar de beterraba que era direcionado para a Europa e o açúcar antilhano que era vendido em grande parte para os Estados Unidos. Assim, um excedente muito grande, a queda nos preços deste produto e a transformação dos grandes consumidores em grandes produtores levaram aos senhores de engenho brasileiros a acentuarem as dificuldades por que passavam ${ }^{4}$. E não faltaram vozes dentre eles para se queixar da gravidade da "crise" que assolava o setor.

Mas, o que chama ainda mais a atenção destes atores são as idéias que defendiam a centralização agrícola e industrial como forma de debelar os principais problemas da produção açucareira brasileira. Assim, este novo sistema produtivo, consubstanciado, no período, no modelo dos engenhos centrais, transformou-se no novo projeto que seria pleiteado tanto pelo Estado quanto pelos produtores.

Isto não significou a inexistência de debates em torno das vantagens e desvantagens destes engenhos centrais ou como este novo processo produtivo seria implantado. André Rebouças ${ }^{5}$ foi um dos mais representativos entusiastas deste novo sistema produtivo, chegando a

\footnotetext{
${ }^{3}$ Esta indústria nascida no início do século XIX conquistou a proteção governamental contra o açúcar de cana, mesmo após o termino do Bloqueio Continental de Napoleão, e desenvolveu-se para satisfazer a demanda europeia. Demais, os produtores de açúcar de beterraba passariam a procurar mercados estrangeiros, o que ocasionaria a rápida quebra dos preços mundiais. Assim, em 1900, os produtores de açúcar mascavo estavam ganhando menos da quarta parte dos preços obtidos há sessenta anos. (EISENBERG, 1977, p. 44).

${ }^{4}$ Prefere-se neste trabalho adotar os termos utilizados no período em análise pelos grandes produtores de açúcar para se autodenominarem-se. Assim, nas suas falas nos congressos e nos textos publicados em periódicos e livretos foi comum que esses homens se apresentassem simplesmente como senhores de engenho, fazendeiros, agricultores, representantes da indústria açucareira, etc. Mas isso não impede que se atente para um importante aspecto da realidade. Essas ideias e planos foram estruturados e colocados em prática somente pelos grandes produtores de açúcar. Assim, pode-se dizer que formavam a elite agrária, ou mais especificamente, a elite açucareira do país.

${ }^{5}$ Rebouças completou sua formação intelectual nos quadros da burocracia militar, na condição de tenente-engenheiro, absorvendo da Escola Militar a crítica fomentada pelo oficialato às instituições imperiais. Durante as décadas de 1860 e 1870, participou, na qualidade de engenheiro civil, ativamente do processo de modernização material do Segundo Reinado, inserido na burocracia de Estado. Nesse caso, destacam-se os projetos para melhorar o abastecimento de água na cidade do Rio de Janeiro e a construção das docas do Mercado e da Alfândega do Rio de Janeiro para facilitar o embarque
} 
fazer um estudo detalhado das benesses da centralização agrícola e industrial. (TRINDADE, 2004). Certo é que, o foco deste debate travado por senhores de engenho e estadistas concentrou-se nas questões relacionadas à modernização como uma forma de recuperar o mercado externo. Rebouças, no entanto, enxergava neste processo, uma reforma social, uma vez que, esses engenhos centrais e fábricas centrais teriam um verdadeiro papel civilizador, seriam verdadeiras escolas práticas, bancos rurais, incentivadores da substituição da mão-de-obra escrava pela livre, dentre outras características positivas.

Na medida em que percebemos a ênfase dada por Rebouças ao que ele chamava de "democracia rural" entende-se a sua preocupação em clarificar o fato de que o sistema dos engenhos centrais seria, na verdade, de autoria de Condorcet $^{6}$, pai da ideia inicial da centralização agrícola e industrial, apesar de muitos senhores de engenho e estadistas atribuírem a invenção no novo sistema produtivo a Cail, da bem conhecida firma Derosne e Cail, de Paris. (REBOUÇAS, 1883, p. 192). Provavelmente este fato fosse decorrente das experiências de Derosne e Cail em algumas colônias, como em Cuba, que permitiram um aumento expressivo da produção de açúcar de cana. Certo é que ao adotaram o princípio da centralização agrícola e industrial, os produtores de açúcar pretendiam aumentar a sua produção qualitativa e quantitativamente e não reorganizar a estrutura social do período. Objetivo este sim, almejado por Condorcet e Rebouças.

Segundo fontes da época, a divisão do trabalho racionalizaria o processo de produção tanto agrícola como industrial, uma vez que, cada agente da produção executaria o menor número de operações possíveis. Rebouças enfatizaria as mesmas vantagens, mesmo que os seus objetivos fossem diversos da maioria dos produtores de açúcar neste momento.

É evidentemente mais fácil, entre 100 senhores de engenho, achar 90 com as habilitações necessárias para bem plantar e colher a cana de açúcar, do que 10 capazes de tirar da cana, pelos sistemas hodiernos, o açúcar e os produtos conexos de modo a obter o máximo lucro. Se assim é, nada mais racional do que aconselhar a esses 90 senhores de engenho que se limitem a ser simplesmente plantadores de cana, deixando aos dez outros explorar a indústria sacarina, que exige conhecimentos técnicos, edifícios, maquinas e aparelhos de elevado custo, isto é, talento e capital, que, por fatalidade, só excepcionalmente se acham reunidos em um só individuo. Em outras palavras: dos 100 engenhos, 90 se reduzirão a plantações de cana e 10 se constituíram

de produtos agrícolas. Importa ressaltar que Rebouças faria parte do círculo social do Imperador e de alguns proeminentes estadistas do período, como o Visconde de Itaboraí. Ademais, seu pai, Antônio Pereira Rebouças tinha grande prestígio na corte, chegando a ser conselheiro do Império. Na década de 1880, projetou-se enquanto reformista social, visando articular o movimento abolicionista a projetos de reforma do estatuto territorial. Ele Participou da fundação da Sociedade Brasileira contra a Escravidão, depois denominada Associação Central Emancipadora e da criação do Clube de Engenharia. Enfim, Rebouças deixou uma vasta bibliografia publicada sobre os mais diversos assuntos, técnicos, sociais, políticos, etc.

${ }^{6}$ Marie Jean Antoine Nicolas Caritat (1743-1794), o marquês de Condorcet, foi um filósofo e matemático francês e um dos principais pensadores da Revolução Francesa. Colocar ano nascimento e morte 
em engenhos centrais. Tal é, em termos bem claros, a reforma que ordena o principio da centralização agrícola, sob o ponto de vista técnico da divisão do trabalho. (REBOUÇAS, 1883, p. 13).

É preciso que se tenha em conta, ademais, que quase a totalidade dos atores da indústria açucareira, considerava uma necessidade mais premente modernizar a parte fabril. A modernização da lavoura, apesar de já ser apontada como um fator importante, não era colocado em primeiro plano. $O$ equilíbrio pensado por Rebouças não foi alcançado. Obviamente uma série de motivos contribuiu para isso, sendo a disparidade entre as inovações adotadas na lavoura e na fábrica um dos mais significativos.

Note-se, porém, que, os defensores do sistema dos engenhos centrais seguiriam nesta mesma linha, mesmo que o processo não tenha sido posto em prática de forma completa. Havia a defesa de que a separação da lavoura e da indústria levaria a prosperidade tanto dos fabricantes de açúcar como dos agricultores, como o que aconteceu em Guadalupe, Martinica, Bourbon, etc. Defesa esta feita pelos principais técnicos do período, como o engenheiro Pedro Dias Gordilho Paes Leme ${ }^{7}$.

\begin{abstract}
Os plantadores serão só lavradores: do que lhes resultará: reunir todos os seus recursos ao trabalho agrícola; remir-se de dispendiosas montagens de fábricas; poupar-se a todos os dissabores, contratempos e prejuízos, inerentes ao penoso trabalho do fabrico; Ter aumentado a receita $50 \%$, obtendo igual aumento do tempo para os trabalhadores da lavoura e vendendo a cana por preço equivalente ao que atualmente alcançam fabricando o produto. (LEME, 1874, p.11).
\end{abstract}

Em verdade, essa busca febril dos senhores de engenho brasileiros por uma maneira de modernizar o setor relacionava-se em grande parte ao desenvolvimento da produção de açúcar de beterraba na Europa. Essa nova cultura sacarina desempenhou, desde o início do século XIX, um importante papel no processo de modernização da indústria açucareira. Com o tempo, as inovações técnicas desenvolvidas para o açúcar de beterraba foram adaptadas para o açúcar de cana. Certamente, estes avanços passaram a ser uma preocupação para os países como o Brasil. Bulamarque $^{8}$, na sua monografia da cana-de-açúcar, já caracterizava esta produção como "esse

\footnotetext{
${ }^{7}$ Pedro Dias Gordilho Paes Leme foi diretor do Jardim Botânico do Rio de Janeiro entre 1887-90 e um dos fundadores do Engenho Central de Sant'Anna. A família Paes Leme fazia parte das mais proeminentes famílias de Vassouras, proprietária de vastas extensões de terras, dentre elas os Correia de Avelar, Wernecks, Ribeiro de Avelar e Teixeira Leite. (STEIN, 1981, p.120).

${ }^{8}$ Frederico Leopoldo Cezar Burlamaque era engenheiro e assumiu os cargos de Professor Jubilado da Escola Central, Brigadeiro reformado, Diretor do Museu Nacional, Secretário Honorário Perpétuo e Presidente da Seção de Agricultura e secretário do IIFA. (FIGUEIROA, 2005).
} 
terrível rival de uma das nossas mais importantes indústrias e fontes de riqueza" e aponta a necessidade dos produtores brasileiros de adotar rapidamente os métodos mais racionais de cultura e os aparelhos e processos aperfeiçoados da produção de açúcar de beterraba. O engenheiro elegeu como um fator preocupante a rapidez das inovações técnicas e, consequentemente, o enorme crescimento da produção de açúcar de beterraba. (BURLAMAQUE, 1862).

Os estudos que apontavam a maior riqueza sacarina da cana, entre 18 a $20 \%$ em relação à beterraba de 8 a $10 \%$, tornam particularmente significativa a defesa de que era o atraso da indústria sacarina brasileira que inviabilizava a concorrência. Era a má cultura da cana, a perda do suco pela adoção de moendas imperfeitas e pelos defeituosos processos e aparelhos ainda utilizados na produção de açúcar, ou seja, o sucesso do açúcar de beterraba estava diretamente relacionado à "economia, que resultou dos aperfeiçoamentos, tanto do processo quanto dos aparelhos de produção" (BURLAMAQUE, 1862, p. 59).

Pode-se dizer que a baixa qualidade do açúcar somada à imposição de alguns países como os Estados Unidos, que passaram a exigir níveis de pureza do açúcar de 96\% (ÁLVAREZ, 2010), impulsionou em grande parte as manifestações favoráveis aos engenhos centrais. Nada é mais ilustrativo desta necessidade do que a afirmação de Rebouças de que o açúcar produzido nestes centrais seria exportado para os Estados Unidos e para a Europa, os dois principais mercados que progressivamente estavam se fechando para o açúcar brasileiro.

Avançando um pouco mais, Rebouças destacaria que o açúcar seria enviado sempre refinado, cristalizado ou em pó. É certo que os altos lucros obtidos pelos países europeus com o beneficiamento do açúcar já era uma das preocupações dos produtores brasileiros, que exportavam um açúcar de baixa qualidade e não conseguiam bons preços no mercado externo. Entende-se, assim, a defesa feita por Rebouças de que as fábricas centrais deveriam preparar os produtos agrícolas para entregá-lo ao comércio nas melhores condições de venda e de lucro. (REBOUÇAS, 1883, p. 1).

A divergência principal entre os produtores de açúcar estava, de modo geral, na forma como estas fábricas centrais deveriam ser montadas e muitos foram os planos: pequenos engenhos centrais espalhados pelas zonas canavieiras que visassem receber a cana de pequenos produtores de açúcar, - agora fornecedores -; grandes engenhos centrais, que concentrassem a produção de uma região; engenhos centrais montados com capital estrangeiro ou financiados pelos próprios senhores de engenho. Rebouças nas suas observações recomendava a aplicação de três modelos:

Os senhores de engenho ou os agricultores de cana de açúcar A, B, C, desejando melhorar o seu sistema de produção e auferir maiores 
lucros, associam-se e entregam a gerência de seus estabelecimentos a uma só pessoa; reúnem todas as suas máquinas na situação mais conveniente para receber a cana de açúcar das plantações, e enviar o açúcar e os produtores conexos ao mercado; formam assim um estabelecimento único, o qual concentra todas as variadas operações, necessárias para tirar da cana de açúcar o máximo proveito [...].

O senhor de engenho A, assaz rico, filantropo e previdente, divide as suas vastas terras em lotes, que vende, afora ou arrenda aos seus emancipados e colonos nacionais ou estrangeiros; confia-lhes todo o trabalho da produção da cana-de-açúcar, concentra toda a sua atenção na fabricação do açúcar e dos produtos conexos; compra as máquinas e os aparelhos necessários para exercer nas melhores condições econômicas a indústria sacarina, e consegue, assim, por seu simples esforço individual, fundar um engenho central. [...].

O Governo provincial ou geral, ou ambos, desejando estimular a iniciativa individual e o espírito de associação dos agricultores, funda, direta ou indiretamente, subvencionando ou garantindo juros, um estabelecimento, com as melhores condições técnicas e econômicas para a produção de açúcar ou café, e determina que este estabelecimento só se ocupe da preparação, e compre aos agricultores circunvizinhos a cana de açúcar ou do café em cereja. Esse estabelecimento que será um centro e um exemplo, um foco de atração e um estímulo, merecerá o nome de engenho central, conforme se ocupar da produção de açúcar ou de café. (REBOUÇAS, 1883, p. 2).

Particularmente no Brasil, a montagem dos engenhos centrais inclinou-se acentuadamente para o primeiro e o segundo caso. O Estado interviria na forma da concessão de auxílios, seja através da garantia de juros até isenção das tarifas aduaneiras. Os modelos propostos por Rebouças podem ser notados no caso do Engenho Central de Porto Feliz. O mais antigo engenho central de São Paulo e que foi fundado em 1878 (SOUZA, 1978) 9, por fazendeiros que tinham origens familiares de seus capitais na cana-de-açúcar (BRAY, 1989, p. 49). O outro modelo seria o Engenho Central de Quissamã, fundado no Rio de Janeiro, pelo Barão de Monte Cedro, José João Carneiro da Silva, membro da tradicional família açucareira Carneiro da Silva, com o seu irmão, o segundo Visconde de Araruama.

\footnotetext{
${ }^{9} \mathrm{O}$ primeiro engenho central inaugurado no Império foi o de Quissaman, em 12 de setembro de 1877, no Rio de Janeiro; o segundo, o de Morretes, em 2 de junho de 1878, no Paraná, o terceiro, em 28 de outubro do mesmo ano, em Porto Feliz, São Paulo e o quarto, foi o Engenho Central de Barcelos, também no Rio de Janeiro, em 1878. O primeiro Engenho Central no Nordeste foi o de Bom Jardim, em Santo Amaro - Bahia, só inaugurado em 21 de janeiro de 1880.
} 
Figura 1- Fachada do Engenho Central Porto Feliz - São Paulo

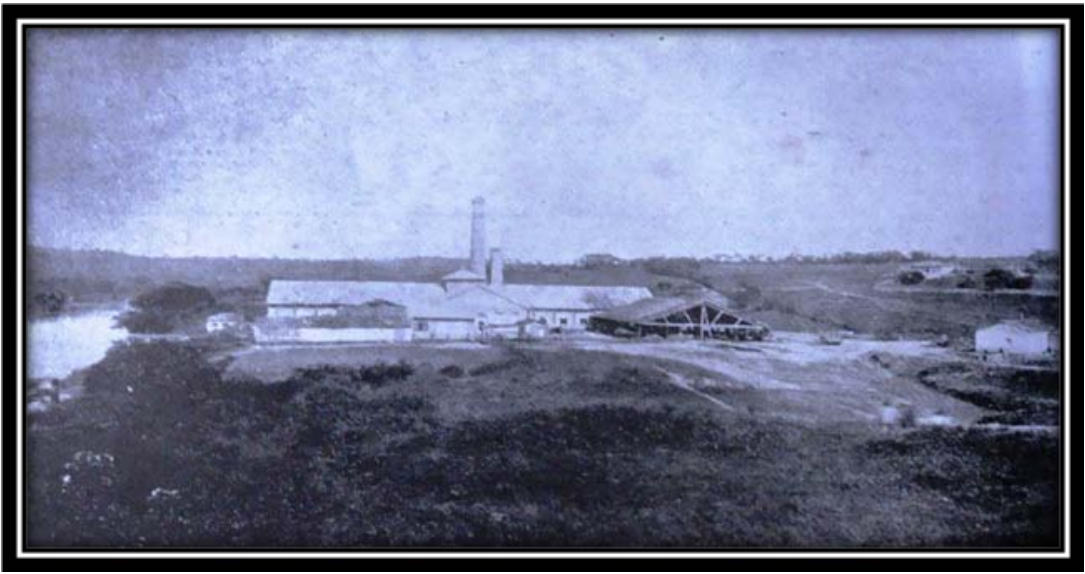

Fonte: Imperial Instituto Fluminense de Agricultura $(1879$, v. 10).

Figura 2- Fachada do Engenho Central de Quissamã -Rio de Janeiro

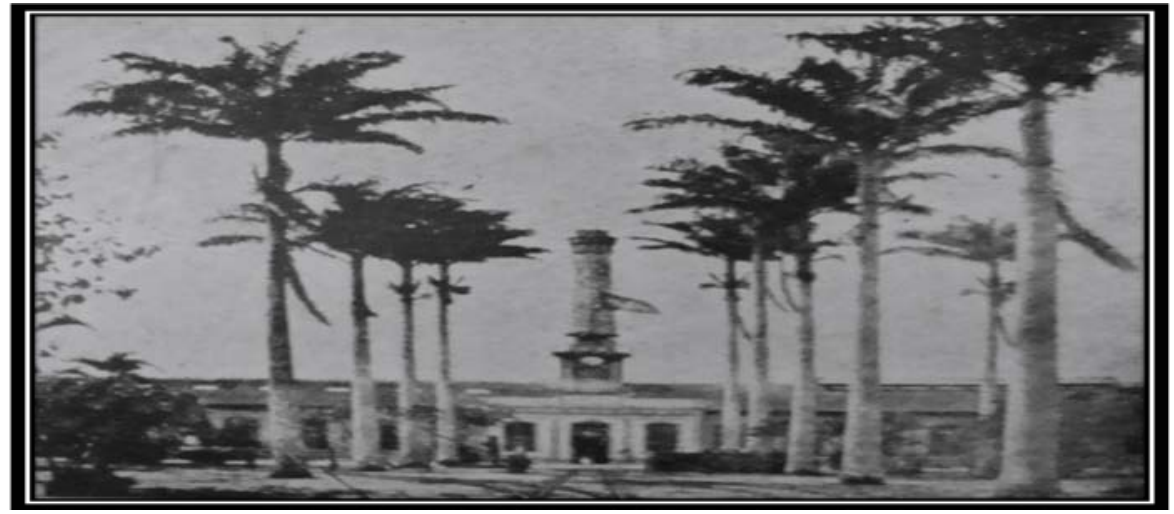

Fonte: Imperial Instituto Fluminense de Agricultura (1879, v. 10).

Para muitos dos defensores da centralização agrícola e industrial, como Rebouças, esse sistema precisava para prosperar de auxílios estatais, sendo que um dos mais importantes seria a concessão de garantia de juros. Assim, é de justificar que para se entender o pensamento de Rebouças sobre este novo sistema produtivo, procure-se analisar como ele esperava que essas mudanças fossem financiadas. Como se sabe, o Brasil, a partir do século XIX, começou a importar tanto a arquitetura das suas fábricas quanto o maquinário necessário. (GAMA, 1979). Naturalmente, como podemos perceber na fala de André Rebouças, em um país onde a falta de capitais era o maior entrave para os interesses da lavoura, - a principal fonte de renda do país -, restava buscar auxílio no capital estrangeiro. Certamente para atraí-lo era necessário um 
estímulo, consubstanciado aqui na adoção do sistema de garantia de juros. Além disso, não se pode deixar de relacionar essa defesa com a conjuntura econômica vivida pelo país, como explicaria Rebouças:

O estado atual das fortunas no Brasil, mesmo na praça do Rio de Janeiro, a mais rica do Império, demonstra a necessidade da garantia de juro, sobretudo nos primeiros anos, durante a execução das obras. Raras são as fortunas, que podem dispensar a renda ou os juros do capital empregado em ações durante um, dois, três ou mais anos. Em regra geral os capitalistas necessitam de toda a renda dos seus capitais para ocorrerem as suas despesas anuais. É necessário, portanto, que, comprando ações de uma companhia, tenham certeza de não ficarem privadas da renda dos capitais nelas empregado (REBOUÇAS, 1874, p. 30).

Soma-se a isso a dificuldade dos agricultores em conseguirem empréstimos a juros baixos e com longos prazos de amortização. A grande desvalorização da propriedade rural, com o término eminente do regime servil, constituía uma obstrução à criação de uma estrutura creditícia de base nacional. (CANABRAVA, 1997, p. 134).

Naturalmente, ao se escorar na lavoura como a sua principal fonte de renda, o Estado buscaria mitigar o problema do crédito agrícola. Vê-se, assim, facilmente, a estreita relação entre o apoio estatal e a modernização do setor açucareiro no Brasil. Assim, começaram as políticas agrícolas voltadas para incentivar a montagem de engenhos centrais através da garantia de juros. Pernambuco e Rio de Janeiro, em 1871; Sergipe, Bahia e Rio Grande do Norte, em 1874 e a lei $\mathbf{n}^{\circ}$ 2687, em 1875, do Estado Imperial.

Nesse caso, as letras hipotecárias seriam negociadas nas capitais européias com garantia de juros de $5 \%$ e amortização no prazo de 30 anos. As companhias montadas no Brasil teriam direito a: garantia ou fiança de juros não superiores a 7\% anuais, pelo prazo de vinte anos, reduzindo-se a garantia a um máximo de $6 \%$ no caso de o juro garantido ou afiançado ter de ser pago em ouro ou ao câmbio de 27 dinheiros esterlinos por $1 \$ 000$ réis. Em contrapartida, os concessionários deveriam cumprir as normas e prazos, para que as concessões não fossem consideradas caducas e perderem, assim, a garantia de juros dada pelo Estado. (BRASIL, 1875).

Ora, André Rebouças, em seu trabalhado intitulado "Garantia de juros: estudo para sua aplicação às empresas de utilidade pública no Brasil”, publicado em 1874, tratava justamente da proficuidade que o sistema de garantia de juros teria no país. Não obstante, para ele as experiências de outros países deveriam ser analisadas e algumas medidas adotadas. 
Em primeiro lugar, a garantia de juros deveria ser vista apenas como uma animação, um auxílio moral quando a empresa dava bons resultados desde o início. Assim, a empresa deveria demonstrar ao Governo que se fundava em cálculos baseados sobre dados estatísticos oficiais e, em orçamento de obras, cuidadosamente executados. Aliás, ela só poderia ser concedida quando as empresas de primeira categoria demonstrarem a impossibilidade de realizá-la sem o apoio do Estado. Ademais, nas empresas menos prósperas, ela só se tornaria efetiva depois da obra terminada ou em todo ou por partes, conforme o contrato e só se realizaria tão somente em relação às somas efetivamente empregadas nas obras.

De acordo com Rebouças, acrescentava-se a tudo isso a necessidade do Governo fiscalizar as empresas garantidas através de engenheiros fiscais e de funcionários que conhecessem o plano de execução da obra. Se houvesse a impossibilidade de orçá-la minuciosamente, deveria ser feito o orçamento de um máximo de capital, prevenindo-se assim a atuação de diretores menos cuidadosos. Nesta mesma linha, a diretoria seria composta por seus concessionários originais e o seu fundador seria o gerente. (REBOUÇAS, 1874, p. 11-30).

Percebemos, nos relatos do período, que, em um primeiro momento, o Governo não adotou as medidas defendidas por Rebouças nas concessões dos engenhos centrais com garantia de juros. Posteriormente, a falta de resultados, que iam desde o grande número de concessões caducas até problemas como a falta de fornecimento da matéria-prima, levou a freqüentes mudanças na legislação e a uma intervenção cada vez maior do Estado.

Nesse sentido, foi aprovado o decreto $\mathrm{n}^{\circ}$. 8.357, de 24 de dezembro de 1881, para as concessões de engenhos centrais, com garantia de juros ou fiança do Estado. Por este regulamento se fixavam as novas bases da garantia de juros, sendo arbitrada uma garantia de 500:000\$000, se o engenho tivesse capacidade para moer diariamente até 200.000 quilos de cana e fabricar, durante a safra, calculada em 100 dias, até 1.000.000 quilos de açúcar; 750:000\$000, se a capacidade se elevasse até o duplo; e 1.000:000\$000, se a capacidade se elevasse até o quádruplo. Seguindo essa mesma linha de normatização defendida por Rebouças, em 1884, instituíram-se as instruções para os engenheiros fiscais. Para facilitar o trabalho, o decreto $\mathbf{n}^{\circ}$. 9307, de 14 de outubro de 1884, distribuía as províncias em três distritos.

Assim, tentativas de regularizar as concessões dos engenhos centrais foram comuns até o final do Império. Em $1^{\circ}$ de dezembro de 1888, um novo regulamento foi aprovado pelo decreto $\mathrm{n}^{\circ} .10 .100$, na qual se proibia a transferência das concessões, salvo depois que a fábrica já estivesse em construção e com a autorização do Governo. Dessa forma, tentava-se limitar as especulações.

Finalmente, o Governo passou a exigir um relatório bem mais completo, numa tentativa de conseguir impulsionar os engenhos centrais. Nestes termos, nas petições para concessão de garantia ou fiança deveriam ser declarados: os municípios escolhidos para situação da fábrica, com informações gerais acerca da produção de cana, açúcar e álcool, quantidade de água potável, 
lenha e outros combustíveis, viação externa ou interna; a capacidade da fábrica ou sistema projetado; a extensão aproximada do sistema das vias férreas e de outros meios de transporte destinados a ligar a fábrica aos estabelecimentos agrícolas e os meios para a realização da empresa.

Ao contrário do ocorrido em outros países citados por Rebouças, - como o Egito-, e apesar da garantia de juros e dos benefícios dados pelo Governo Imperial, a política dos engenhos centrais quase não se desenvolveu. No gráfico, percebe-se que, ainda em 1889, havia fortes entraves para a efetivação da garantia de juros. Essas foram dadas prioritariamente nos principais centros produtores e em muitos casos não se consolidaram de fato. No final do Império, haviam sido concedidos apenas 13 mil novecentos e cinqüenta contos de reis, dos 30 mil anunciados na lei n. $^{\circ} 2687$ de 1875 . Vários foram os motivos alegados pelo Governo para declarar as concessões caducas, principalmente atraso das obras.

Acerca de tudo o que foi exposto, não se pode deixar de pressentir que as preocupações e os apontamentos de Rebouças tinham uma razão de ser confirmada pelo passar dos anos. O seu modo de pensar divergia do Governo até nos valores referentes à garantia de juros, como podemos perceber no gráfico abaixo. Entende-se assim, as críticas feitas à lei 2687. Críticas estas que se confirmariam rapidamente, já que o sistema dos engenhos centrais não duraria quinze anos no Brasil.

Gráfico 1- Garantia de juros efetiva pelo Governo 1889

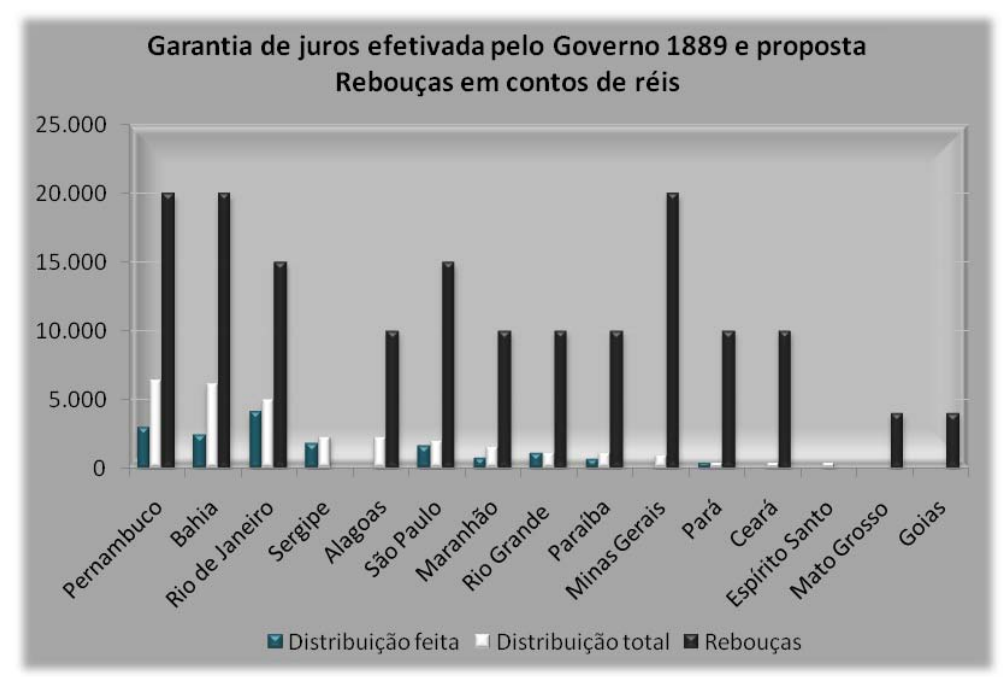

Fonte: Rebouças (1883, p. 270). 
Em que pese à harmonia da proposta de Rebouças percebe-se que os duzentos mil contos de réis adaptavam-se melhor aos custos destes maquinismos. Ademais, ao propor a priorização de áreas que não tinham uma tradição açucareira voltada para o mercado externo, como Minas Gerais, Rio de Janeiro e São Paulo, Rebouças vislumbrava o caminho da expansão futura do açúcar nestas áreas. A diversificação da produção seria um dos pontos levantados. Por outro lado, as províncias já produtoras, como Pernambuco e Bahia deveriam modernizar a sua produção e ao invés de engenhos de má qualidade montar engenhos centrais. Para ele, o caso dos vinte e dois engenhos centrais do Egito era um exemplo a ser seguido pelo Brasil, pois produziam 146.250.000 $\mathrm{kg}$, quase o triplo dos 893 engenhos da Bahia, dos quais apenas 282 eram a vapor. Nesse sentido, ele defendia que seria necessário realizar uma reforma radical, reduzindo todos esses engenhos obsoletos a umas vinte fábricas centrais, que contassem com mão-de-obra especializada e aparelhos aperfeiçoados ao invés de:

Um pessoal enorme, um material velho, mesquinho, insuficiente e incapaz! Tudo isto mal gerido e mal situado; algumas vezes a distâncias impossíveis das boas vias de comunicação! Quanta máquina a vapor obsoleta! Que desperdício de combustível! Quantas moendas verticais deixando no bagaço quase todo o açúcar! Quanto mestre de açúcar ignorante e rotineiro! E como síntese e corolário de tudo isso um desperdício de tempo, de capital e de pessoal nesta indústria, que exatamente pelo braço e pelo crédito territorial. (REBOUÇAS, 1883, p. 161).

Se porventura, Rebouças tivesse considerado as singularidades de alguns dos países que implantaram o sistema dos engenhos centrais em relação ao Brasil entenderia que a idéia não prosperaria no país nem naquele momento nem em outro. Em sua maioria, os países citados por ele já possuíam um mercado cativo e uma maior facilidade de conseguir elevados capitais, como foi o caso de Cuba que contou com o mercado e os investimentos americanos. Ocorre que, no Brasil, a visão da vocação agrícola do país, - fruto de um processo de longa duração -, incentivaria não só Rebouças, mas vários outros homens do período a defenderem a superioridade da lavoura de cana-de-açúcar brasileira.

Mas em todas as partes do mundo, já o demonstramos exuberantemente em Guatemala, em Martinica, em Mauricius, em Java, no México, em Cuba, os engenhos centrais, as fazendas centrais, as fábricas centrais têm dado 16 a $48 \%$ de renda líquida; seria fazer injustiça ao Brasil ousar supor que neste país a mesma instituição não dê $7 \%$. Assim, pois, em última análise, o Governo imperial não fará mais que prestar o seu crédito; e, quando muito, despender algumas 
centenas de contos de réis com o pagamento das garantias de juros nos primeiros meses de instalação. (REBOUÇAS, 1883, p. 293).

Ademais, na visão de Rebouças, às fábricas centrais também pesaria a responsabilidade de funcionar como bancos. Eles teriam sempre capital excedente ou crédito suficiente para satisfazer as despesas do custeio, não precisando recorrer às hipotecas e gozariam de recurso de emissão de obrigações se houvesse necessidade de capitais. Além disso, deveriam funcionar como bancos para os lavradores, colonos ou fornecedores de cana, quando fossem necessárias pequenas quantias para utensílios e ferramentas, e adiantamento de salário. Isto criaria um vínculo e uma dependência do lavrador com a companhia. Assim, "As fazendas centrais, os engenhos centrais e as fábricas centrais, serão verdadeiros bancos rurais, disseminados por todo o Brasil e em contato direto com todas as categorias de lavradores". (REBOUÇAS, 1883, p. 306).

Alguns engenhos centrais chegariam a realizar empréstimos para os seus colonos e fornecedores de cana. A própria lei que regularizou os engenhos centrais previa esta função. No artigo segundo, parágrafo terceiro da lei $\mathrm{n}^{\circ} 2687$, impõe-se a criação de um fundo de $10 \%$ do valor da garantia de juros, a ser dado por empréstimo, a curto prazo e a juros de $8 \%$ ao ano, aos plantadores e fornecedores de cana como adiantamento para auxílio dos gastos da produção. A lei impunha que o empréstimo não poderia ser de mais de $2 / 3$ do valor da safra de cada lavrador e a fiança seria os frutos pendentes, ou seja, neste caso, as colheitas futuras e instrumentos da lavoura.

Curiosamente estas medidas não foram suficientes para melhorar o recebimento da matéria-prima, o que se tornaria um dos mais sérios problemas dos engenhos centrais. A possibilidade do fornecedor de cana produzir aguardente, rapadura ou açúcar bruto, - produtos com um mercado certo -, retirava em grande parte o controle dos proprietários dos engenhos centrais.

Da mesma forma, a falta de mão-de-obra especializada seria um sério problema neste momento. As empresas responsáveis pela venda do maquinário enviavam para o Brasil os engenheiros e técnicos especializados na montagem deste maquinário e muitos chegaram a trabalhar nos engenhos centrais. Houve uma tentativa por parte do Governo Imperial de criação de escolas agrícolas, mas a maioria ou não chegou a sair do papel ou não teve uma longa duração. Na medida em que a escravidão não duraria muito mais tempo, Rebouças enxergava nestas fábricas centrais uma forma de educar os ingênuos e uma "benéfica e poderosíssima influência para a colonização". (REBOUÇAS, 1883, p. 368).

Não é possível encarecer por demais as vantagens das escolas dos engenhos centrais, das fazendas centrais, e dos estabelecimentos 
análogos para a educação técnica dos filhos dos nossos agricultores. Todas as horas, que não forem empregadas nos estudos escolares, serão aproveitadas em exercícios no campo e nas oficinas. Desde os seus primeiros anos o menino se familiarizará com a tecnologia e com o emprego de todos os utensílios e de todas as máquinas rurais. Crescerá, por assim dizer, em um meio agrícola, como crescem as aves no ar e os peixes no mar (REBOUÇAS, 1883, p. 374).

Para ele, a falta de conhecimentos era um dos grandes males da agricultura nacional. Assim, as suas observações sobre educação perpassam pela necessidade dos filhos dos fazendeiros fazerem cursos afins ao invés de freqüentarem a faculdade de direito. Evitar-se-ia também o êxodo rural. Esta vocação educacional dos engenhos centrais é bem ilustrada em um relatório do engenheiro fiscal Luis Monteiro Caminhoá quando se refere ao engenho central de Capivari, um exemplo a seu ver a ser seguido. O engenheiro apontava que esta fábrica fazia lembrar as fábricas da Europa e dos Estados Unidos e que no projeto original se previa a construção de uma escola pública e de uma escola agrícola. Assim, propôs a construção no engenho de um asilo para ingênuos e meninos desamparados.

A fundação deste asilo em tal circunstância, além de ser um ato benemérito, é de grande vantagem nas proximidades do engenho central, já por ser uma escola prática de uma indústria nacional que promete florescer, e na qual escola os meninos adquirem hábitos de trabalho e moralidade, tornando-se operários úteis em pouco tempo, já por se exercitarem na cultura da cana, onde os melhores vão sendo exigidos. (CAMINHOÀ, 1885, p. 13).

Não poderia deixar de passar despercebida que a adoção da centralização agrícola e industrial estaria ligada diretamente a substituição dos escravos pelo trabalho livre. A legislação adotada para a concessão dos engenhos centrais dispunha que não se poderia possuir nem empregar escravos na construção das obras e serviços da fábrica. ${ }^{10}$ Para Rebouças havia a necessidade de reformas sociais, econômicas e financeiras, pois só assim, aproveitar-se-ia o próprio trabalhador nacional que vivia no sertão, além de atrair colonos estrangeiros pelo acesso a propriedade do solo.

Naturalmente, Rebouças relacionaria em grande parte o atraso da lavoura da cana de açúcar a escravidão. Ela "seria ignorante, rotineira, emperrada, incapaz de emulação e de qualquer esforço progressista!" A consequência imediata seria a péssima qualidade do açúcar brasileiro, que até 1875, ainda eram enviados à Europa em sacos sujos ou em caixas de difícil transporte e contendo um açúcar que quase não se distinguia da terra a não ser pelo cheiro fétido e pelas moscas ao seu redor.

\footnotetext{
${ }^{10}$ Decreto $\mathrm{n}^{\circ} .8 .357$, de 24 de dezembro de 1881 .
} 
Se destes princípios gerais da Ciência Econômica fazemos adequada aplicação às circunstâncias especiais deste Império, achamos que a grita falta de braços significa realmente uma aspiração retrógrada pelos misérrimos tempos, em que era possível comprar um homem por $200 \$$ ou $300 \$$ e também a resistência esculta e rotineira para a subdivisão da grande propriedade. Ora, de um lado é absolutamente impossível voltar aos nefandos tempos do tráfico africano; e, de outro lado, todo o progresso agrícola tem por principal elemento a subdivisão do solo e a prosperidade da democracia rural. Eis aí francamente a verdade. (REBOUÇAS, 1883, p. 381).

A mudança da mão de obra escrava para o trabalho livre não significou um problema somente para o Brasil. Reinaldo Monzote refere-se a um quadro parecido em Cuba e destaca que o melhoramento no método de cultivo estava em consonância com a necessidade de substituir a mão-de-obra escrava por trabalhadores livres. O sistema dos centrais de separação da lavoura e da fábrica e o cultivo de cana de açúcar em pequena escala e por cultivadores livres significou uma alternativa ao emprego de mão-de-obra escrava. (MONZOTE, 2002, p. 186-213).

É preciso, contudo, lembrarmos que o funcionamento de uma forma de produção baseada em métodos passados de pai para filho desde os tempos da colônia acabaram levando o setor agrícola brasileiro a se escorar na produtividade dos solos férteis oriundos das derrubadas das matas e de uma mão-de-obra que poderia ser explorada até o seu limite. $O$ esgotamento dos solos em algumas regiões, como no Vale do Paraíba, o escasseamento das matas que serviam de lenha para os engenhos e o eminente fim da escravidão desempenhariam um papel de sinalizador da necessidade de mudanças. Ademais, essas questões explicam a maior articulação do setor com o Estado na procura de políticas agrícolas que estimulassem a recuperação econômica da indústria sacarina (SNA, 1911).

O Barão de Barcellos, fazendeiro cuja família estava ligada a produção açucareira, apontava a fragilidade econômica do país em função do predomínio das técnicas rotineiras de cultivo do solo passadas de geração em geração. Ao destacar que as técnicas de cultivo tradicionais não seriam mais viáveis economicamente, o autor explicava a perda da hegemonia do Brasil no mercado externo de açúcar.

Os nossos pais, porém, tiveram o trabalho que pagavam com alimento e vestuário, nossos pais fabricavam e vendiam o açúcar sem concorrência de poderosa rivalidade, nossos pais tinham a fertilidade do solo, que se tem esgotado pelo prolongado plantio, nossos pais enfim tinham principalmente a superioridade de conhecer os rudes e imperfeitos instrumentos que hoje não bastam. Nesta triste 
alternativa não há outro meio - apreender e aperfeiçoar os meios de cultivo e de fabrico ou abandonar este gênero de produção. (BARCELLOS, 1887, p. 12-13).

Interessa notar, o destaque que a agricultura paulista já começava a ter, tornando-se uma referência para as outras províncias, uma vez que, as inovações técnicas eram adotadas com maior facilidade e, consequentemente, percebia-se claramente as vantagens oriundas da adoção deste novo maquinário. Para Rebouças, um exemplo ilustrativo seria o caso de Limeira, "onde existem cerca de 40 máquinas, movidas a vapor, e um sem número de outras, que se movem por meio de água e de animais, e onde é comezinho o trabalho aratório; na grande e pequena lavoura". Ademais, é neste clima de conflito entre o atraso e o progresso ${ }^{11}$ que ele defende a necessidade da modernização penetrar nas práticas comerciais e agrícolas, uma vez que,

Ter telégrafos e locomotivas, lavrando a terra e exportando os seus produtos, como há cem anos atrás, é fazer, pelo menos, um papel ridículo perante o mundo civilizado, que hoje houve cada uma das nossas palavras, vê cada um dos nossos atos, e sente cada uma das nossas pulsações, sob a ação mágica da eletricidade. (REBOUÇAS, 1883, p. 75).

Em 15 de abril de 1875, o deputado Cardoso de Meneses pediu que se nomeasse a Assembléia Legislativa uma comissão de seis membros para estudar os principais problemas da lavoura. O "Parecer" dessa comissão, dirigida pelo próprio deputado, defendeu a instalação de escolas profissionais, estradas, redução de impostos, braços, capitais e a instalação de engenhos centrais. Seguindo os mesmos apontamentos do parecer de 1875, Rebouças traçou um perfil semelhante das necessidades da lavoura. Uma das referências convergentes seria a falta de estradas e a importância dos caminhos de ferro para o Brasil. Dizia ele que:

Uma rede de vias de comunicação aperfeiçoadas é um elemento indispensável à liberdade de trabalho: é um agente infalível e da máxima energia para o desenvolvimento da prosperidade nacional. Ouvi o grande mestre da ciência do progresso neste sublime e inteiramente novo ponto de vista do grande problema das vias de comunicação. (REBOUÇAS, 1883, p. 391).

\footnotetext{
${ }^{11} \mathrm{O}$ atraso e a rotina passaram nestes anos a serem vistos como a contraposição da ideia do progresso, - tão em voga neste momento na Europa. Deve-se lembrar que um grande número de países foi influenciado por uma aura de modernidade que se sustentou em parte no caráter missionário do progresso.
} 
Ademais, a crítica feita ao Estado ${ }^{12}$ por restringir à política de auxilio à lavoura com base na centralização agrícola e industrial apenas ao açúcar foi levantada por outros importantes representantes dos produtores de açúcar no período. Milet, engenheiro e produtor de açúcar do Norte, defendeu as mesmas idéias discutidas por Rebouças, ou seja, que os capitais garantidos pelo Governo deveriam ser muito maiores e não se restringirem as fábricas centrais. Ademais, o Estado deveria ser responsável por um plano geral de viação e preparar o país para a implantação de colonos-proprietários. No entanto, também para ele, as fábricas centrais seriam o único meio de transformar a lavoura de cana, habilitando-a para o trabalho livre. (MILET, 1876).

Nas palavras de Rebouças "são, portanto, reformas sociais, econômicas e financeiras, ditadas pelo mais puro espírito de liberdade e de progresso, os únicos agentes capazes de fundar sobre sólidas bases a prosperidade da agricultura nacional". (REBOUÇAS, 1883, p. 409). Por outro lado, acredita-se que o próprio Rebouças entendia que a passagem da mão-de-obra escrava para a livre poderia ser apropriada para atender aos interesses dos grandes proprietários de terra. Entende-se, assim, a sua preocupação com uma reforma social. Ao defender a separação entre lavoura e indústria, os grandes produtores de açúcar propunham principalmente que os pequenos e médios produtores de açúcar transformassem-se em fornecedores de cana, além da criação da figura do colono, que podia trabalhar em terras dos engenhos, mas que tinham a obrigatoriedade de entregar as suas canas. Naturalmente, os interesses desses senhores de engenho passavam por um controle da mão de obra. Seria uma forma de utilizar o colonato e os fornecedores de cana como um compensador dos riscos da produção. (LIMA SOBRINHO, 1971). ${ }^{13}$

Importa lembrar que essas idéias tiveram força no mesmo momento em que os mercados mundiais se fechavam para o açúcar brasileiro e o mercado interno teve que comportar essa produção. Sabe-se, também, que os produtores de açúcar bruto, rapadura e aguardente, tornaramse grandes concorrentes dos engenhos centrais. Deste modo, esse novo sistema de trabalho significaria também a transformação dos produtores concorrentes em meros fornecedores de cana. Neste particular, Ruy Gama frisa que se acentuaram as diferenças entre plantadores e senhores de engenho, existentes desde o início do período colonial, pelos privilégios e obrigações dadas às concessões dos moinhos. "A regulamentação das relações entre o engenho, os lavradores de 'partido' e os fornecedores de lenha, nunca deixou de existir”. (GAMA, 1979, p. 327).

Interessa notar que a "vocação agrícola do país" transformar-se-ia na bandeira principal desses atores, no entanto, devido à própria influência externa, ela estaria imbricada com a defesa da modernização da agricultura brasileira. Na verdade, a idéia do progresso era compartilhada pelos segmentos que compunham essa elite como uma forma de recuperar os tempos áureos e

\footnotetext{
${ }^{12}$ Embora os produtores de açúcar do Norte ainda tivessem uma certa influência política, deve-se considerar que nem todas as suas demandas eram atendidas. Outro aspecto a ponderar era a crescente influência dos cafeicultores da região Sul. Nesse sentido, as queixas contra o Estado passavam desde a falta de crédito para a remodelação dos engenhos até a diminuição dos impostos.

${ }^{13} \mathrm{O}$ colonato foi adotado com sucesso em alguns países como Cuba.
} 
solucionar os seus principais males (BRASIL. Camara dos Deputados, 1875) ${ }^{14}$. Nesse sentido, a produção açucareira difere em grande parte do restante da chamada grande lavoura, uma vez que, o seu processo de beneficiamento tornou-se cada vez mais complexo e mecanizado durante o século XIX.

O atraso brasileiro em relação aos outros produtores, como Cuba, colocaria dentro do universo das questões vitais, a qualidade do maquinário, que necessariamente teria que ser importado de companhias estrangeiras. Neste caso, para muitos dos senhores de engenho era a falta de investimentos que prejudicava a lavoura nacional e a falta de iniciativa do Estado. Parece, pois, que se possa dizer que também para Rebouças, o atraso do país era creditado em grande parte à falta de políticas do Estado Imperial.

Os engenhos centrais de Java são citados entre os melhores. Há engenhos centrais não só nas colônias francesas e inglesas como até no México, na ilha de Cuba, e na Louisiana. Nos estados do Sul da República Norte-Americana os engenhos centrais estão pagando os prejuízos da guerra de emancipação. Como em tudo que é um progresso, como em caminhos de ferro, como em telégrafos, este Império, emperrado e rotineiro, será talvez o último país do mundo a ter engenhos centrais. (REBOUÇAS, 1883, p. 199).

Não obstante a afirmação de Rebouças, percebe-se a importância das políticas imperiais no processo de modernização em curso. A posição da agricultura, neste momento, como o único provedor de divisas do país, explica o condicionamento do Estado em auxiliar a modernização da produção açucareira, principalmente como uma forma de incrementar a sua participação no mercado externo. Ademais, a atuação significativa de homens, ligados direta ou indiretamente à elite rural, nos quadros do Governo, permitiu a agricultura solicitar medidas de auxílio.

Entretanto, os atrasos e as delongas para que muitas destas políticas fossem colocadas em prática, aprofundariam ainda mais a sensação de abandono e crise da lavoura. $O$ surto de modernização industrial no setor açucareiro ocorreu com um atraso de trinta anos em relações aos principais concorrentes do Brasil. (GNACCARINI, 1997, p. 107) ${ }^{15}$. Quando os resultados

\footnotetext{
${ }^{14}$ Assumindo esta desvantagem produtiva, em 15 de abril de 1875, o deputado Cardoso de Meneses pediu que se nomeasse a Assembléia Legislativa uma comissão de seis membros para estudar os principais problemas da lavoura. O "Parecer" dessa comissão, dirigida pelo próprio deputado, defendeu a instalação de escolas profissionais, estradas, redução de impostos, braços, capitais e a instalação de engenhos centrais.

${ }_{15}$ Gnaccarini destaca que a partir de 1870 , "ao iniciar-se este segundo período de expansão, quando tem lugar uma verdadeira revolução industrial na economia açucareira nordestina, outros países produtores, no meio tempo, já se haviam aparelhado, de modo a vincular-se aos mercados metropolitanos. O açúcar de beterraba, que no mercado da Inglaterra entrava em 1885, com 50\%, cinco anos depois detinha $90 \%$; e no mercado dos Estados Unidos, cresce de $10 \%$ para $25 \%$, entre 1884 e 1889 . Além disso, vão sendo os açúcares de cana brasileiros progressivamente substituídos , nesses dois principais consumidores, por açúcares de cana dos países coloniais, como Cuba, Porto Rico e Filipinas, em que
} 
começaram a surgir, o Regime Político já não era mais o mesmo e os engenhos centrais transformaram-se em usinas. A própria fala do Ministro da Agricultura, Manoel Buarque de Macedo, denota tanto uma preocupação com o atraso da agricultura brasileira como a necessidade de políticas mais acertadas. ${ }^{16}$

Na situação atual de nossa grande lavoura, quando uma profunda evolução social se opera, quando completamente se transformam as condições do trabalho rural, quando países análogos ao nosso, com produções similares, procuram progredir por todos os meios, mediante máquinas e processos os mais aperfeiçoados, que as ciências - a química, física e a mecânica - em suas variadas aplicações, tem posto ao serviço da indústria agrícola, conservamo-nos estacionários no meio desse grande movimento, sem ao menos empenharmos os esforços ao nosso alcance para evitar que enfraqueçam ou se estanquem as fontes de produção nacional, seria, senhores, permiteme dizê-lo, não somente um erro, mas um grave crime, perante o tribunal da geração vindoura. (BRASIL. Camara dos Deputados, 1879, p. 125$)^{17}$.

Consoante com o pensamento dos principais atores ligados à agricultura, Rebouças ressaltaria questões como os engenhos centrais e a garantia de juros. Dedicou-se muita atenção às idéias de progresso defendidas por Rebouças, a fim de mostrar que, embora pesasse sempre em suas obras a questão servil, a modernização do país em si se constituía em uma das suas principais preocupações. Certamente que na maioria das vezes, estas questões estão entrelaçadas, mas seria impossível admitir que também não houvesse um direcionamento para as idéias em torno do progresso, fundamentalmente enastradas pelos atores deste período as novas formas de produção e as inovações técnicas.

Não obstante, os propósitos defendidos por ele não eram os mesmos da maioria dos senhores de engenho e estadistas. Ao apontar, a necessidade de uma reforma social para “o desenvolvimento e para a prosperidade da democracia rural no Brasil,", Rebouças distanciava-se do sonho dos principais membros da elite agrária brasileira. A idéia de uma modernização pelo alto, na qual as bases sociais seriam estanques, apesar de algumas mudanças serem necessárias, foi o

predominavam capitais norte-americanos diretos, ou Java, Índias Ocidentais Britânicas e Antilhas Inglesas, nos quais eram majoritários interesses diretos de origem inglesa e holandesa".

${ }^{16}$ Manoel Buarque de Macedo era oriundo de uma família ligada tanto ao comércio quando a produção de açúcar em Pernambuco e Alagoas.

${ }^{17}$ Fala do Exm. Sr. Ministro da Agricultura.

${ }^{18}$ Rebouças deixava claro em seus trabalhos que a abolição dos escravos não era o único passo que deveria ser dado. Para ele era importante que esses ex-escravos tivessem acesso a terra, ou seja, uma redistribuição das terras do país, ou seja, a eliminação dos grandes latifúndios - o que chamava de "democracia rural". Se as suas ideias encontrava-se muitas vezes próximas aos dos senhores de engenho quando defendia o sistema de garantia de juros para financiar a modernização da agricultura brasileira e a centralização agrícola e industrial através da introdução dos engenhos centrais, o seu pensamento distanciavam-se completamente destes outros atores quando propunha uma nova estrutura social. 
modelo adotado no Brasil. E este pensamento, de modo geral, inviabilizou em grande parte o sucesso da centralização agrícola e industrial no país. É certo que a retomada da concentração das terras nas mãos dos fabricantes de açúcar, agora chamados usineiros, demonstra que sem uma reforma social, o modelo de centralização agrícola e industrial nos moldes pensados por Rebouças não conseguiria ser efetivado na prática.

\section{Referências}

ÁLVAREZ, Alejandro García. Café e Cidades: experiências em Cuba. In: SEMINÁRIO DE HISTÓRIA DO AÇÚCAR: Produção, Trabalho e Estrutura Fundiária, 3., São Paulo. Relatório... São Paulo, 2010.

BARCELLOS, Domingues Alves (Barão de). A crise do açúcar: ligeiras considerações pelo Barão de Barcellos. Campos: Lith. e Typ. de Carlos Hamberger, 1887.

BRASIL. Coleção das leis do Império. Rio de Janeiro: Imprensa Nacional, 1875-1889.

BRAY, Silvio Carlos. A formação do capital na agroindústria açucareira de São Paulo: Revisão dos paradigmas tradicionais. Tese (Livre Docência) - Instituto de Geociências e Ciência exatas, UNESP, São Paulo, 1989.

BURLAMAQUE, F. L. C. Monografia da cana de açúcar. Rio de Janeiro: Typ. De N. L. Vianna e Filhos, 1862.

BRASIL. Câmara dos Deputados. Comissões de Fazenda e Especial. Parecer e projeto sobre a criação de bancos de crédito territorial e fábricas centrais de açúcar apresentados a Câmara dos Srs. Deputados na sessão de 20 de julho de 1875 pelas comissões de fazenda e especial nomeada em 16 de abril de 1875. Rio de Janeiro: Typ. Nacional, 1875.

. Sessão de 1879. Rio de Janeiro: Tipographia Nacional, 1879.

CAMINHOÁ. Luis Monteiro. Relatório do Terceiro Distrito de Engenhos Centrais apresentado por Luis Monteiro Caminhoá, engenheiro fiscal. In: $1^{\text {a }}$ SESSÃO DA $19^{\text {a }}$ LEGISLATURA PELO MINISTRO E SECRETÁRIO DOS NEGÓCIOS DA AGRICULTURA, COMÉRCIO E OBRAS PÚBLICAS JOÃO FERREIRA DE MOURA. Relatório... Rio de Janeiro: Imprensa Nacional, 1885.

CANABRAVA, Alice. A grande lavoura. In: HOLANDA, Sérgio Buarque de (Org.). História Geral da Civilização Brasileira. Rio de Janeiro: Bertrand Brasil, 1997. v. 6.

EISENBERG, Peter L. Modernização sem mudança: A indústria açucareira em Pernambuco (18401910). Rio de Janeiro: Paz e terra, 1977.

FIGUEIRÔA, Silvia Fernandes de Mendonça. Ciência e Tecnologia no Brasil Imperial. Varia História, Belo Horizonte, v. 21, n. 34, p. 437-455, jun. 2005.

GAMA, Ruy. Engenho e tecnologia. São Paulo: Livraria Duas Cidades, 1979. 
GNACCARINI, J.C. A. A economia do açúcar: processo de trabalho e processo de acumulação. In: FAUSTO Boris. (Org). História Geral da Civilização Brasileira. o Brasil Republicano: estrutura de poder e economia (1889-1930). Rio de Janeiro: Bertrand Brasil, 1997. v. 8.

IMPERIAL INSTITUTO FLUMINENSE DE AGRICULTURA. Revista Agrícola do Imperial Instituto Fluminense de Agricultura. Rio de Janeiro: Typographia Litteraria, v. 10, 1879.

LEME, Pedro Dias Gordilho Paes. Engenhos Centrais na Província do Rio de Janeiro. Rio de Janeiro: Typ. G. Leuzinger \& Filhos, 1874.

LIMA SOBRINHO, Barbosa. Dos engenhos centrais às usinas de açúcar de Pernambuco. Rio de Janeiro: Separata de Jurídica, 1971.

MILET, Henrique Augusto. Auxílio à lavoura e crédito rural. Recife: Typographia do Jornal do Recife, 1876.

MONZOTE, Reinaldo Funes. Tierras cansadas y quemadores de bagazo verde. La interacción com El médio natural y los câmbios em La industria azucarera cubana desde mediados del XIX. In: PIQUERAS, José A. (Org.). Azúcar y esclavitud em El final del trabajo forzado. México: Fondo de Cultura Económica, 2002.

REBOUÇAS, A. Garantia de juros: estudo para sua aplicação às empresas de utilidade pública no Brasil. Rio de Janeiro: Typographia Nacional, 1874.

. Agricultura Nacional, Estudos Econômicos, Propaganda abolicionista e democrática. Rio de Janeiro: A. J. Lamoureux \& co., 1883.

SNA. Legislação agrícola do Brasil. Rio de Janeiro: Imprensa Nacional, 1911.

SOUZA, Jonas Soares de. Uma empresa pioneira em São Paulo: O engenho central de Porto Feliz. Edição comemorativa do centenário do engenho central de Porto Feliz (1878-1978). São Paulo, 1978. v. 7. (Coleção Museus paulistas).

STEIN, Stanley J. Grandeza e decadência do café no Vale do Paraíba. São Paulo: Brasiliense, 1981.

TRINDADE, Alexandre Dantas. André Rebouças: da engenharia civil a engenharia social. Tese (Doutorado) - IFCH/UNICAMP, Campinas, 2004.

Recebido em 10/10/2011

Aprovado em 01/05/012 